\title{
PEGARUH KONSENTRASI HPMC (HIDROXY PROPYL METHYL CELLULOSE) SEBAGAI GELLING AGENT DENGAN KOMBINASI HUMEKTAN TERHADAP KARAKTERISTIK FISIK BASIS GEL
}

\author{
Indri Pramita R*, Victoria Yulita F, Nur Mita, Adam M. Ramadhan \\ Laboratorium Penelitian dan Pengembangan FARMAKA TROPIS, Fakultas \\ Farmasi Universitas Mulawarman, Samarinda, Kalimantan Timur \\ *Email: indripramitarahmawati@gmail.com
}

\begin{abstract}
ABSTRAK
Sediaan gel yang baik dapat diperoleh dengan cara memformulasikan beberapa jenis bahan pembentuk gel, namun yang paling penting untuk diperhatikan adalah pemilihan gelling agent. HPMC (Hidroxy Propyl Methyl Cellulose) merupakan gelling agent yang sering digunakan dalam produksi kosmetik dan obat karena dapat menghasilkan gel yang bening, mudah larut dalam air, dan toksisitasnya rendah. Penelitian ini bertujuan untuk mengetahui konsentrasi HPMC sebagai gelling agent dengan kombinasi humektan yaitu gliserin dan propilen glikol, yang memiliki karakteristik fisik yang sesuai dengan persyaratan. Formulasi gel dibuat dengan variasi konsentrasi HPMC 3\%, 5\% dan 7\%, selanjutnya dilakukan evaluasi sifat fisik yang meliputi viskositas, $\mathrm{pH}$, daya sebar, organoleptis, homogenitas. Evaluasi fisik dilakukan selama 4 minggu pada suhu kamar. Hasil yang diperoleh menunjukan bahwa basis gel dengan konsentrasi HPMC 3\% memenuhi persyaratan dengan nilai viskositas yaitu 4,69 $\pm 0,14 \mathrm{~Pa}$., nilai $\mathrm{pH}$ yaitu 5,17 $\pm 0,02$, daya sebar yaitu $32,98 \pm 0,85 \mathrm{~cm}$, organoleptis yaitu berwarna bening, tidak memiliki bau dan berbentuk agak cair, serta homogen.
\end{abstract}

Kata Kunci : Gel, HPMC (Hidroxy Propyl Methyl Cellulose), gelling agent

\section{ABSTRACT}

Ideal gel formulation can be obtained by formulating some kind of gelling material, but the most important thing to note is the selection of a gelling agent. HPMC (Hidroxy Propyl Methyl Cellulose) is a gelling agent that is commonly used in the production of cosmetics and drugs, because it can producea gel that is clear, easily soluble in water, and has a low toxicity. This study aimed to obtain the concentration of HPMC as a gelling agent with a combination of humectant that is Glycerin and propylen glycol that has a physical characteristics in accordance with the stipulated requirements. Gel formulations made with HPMC concentration variation of 3\%, 5\% and 7\%, further evaluation of physical properties include viscosity, $\mathrm{pH}$, dispersive power, organoleptic test, and homogeneity. Evaluation gel base done for 4 weeks. The results of stability tests show the base gel with a 
concentration of 3\% HPMC has a good standard for viscosity is 4,69 $\pm 0,14$ Pa.s, $\mathrm{pH}$ is 5,17 $\pm 0,02$, dispersive power is $32,98 \pm 0,85 \mathrm{~cm}$, organolepticis not colored, don't have smell and rather liquid, and homogeneous.

Keywords : Gel, HPMC (Hidroxy Propyl Methyl Cellulose), gelling agent

\section{PENDAHULUAN}

Gel mempunyai sifat yang menyejukkan, melembabkan, mudah penggunaannya, mudah terpenetrasi pada kulit sehingga mampu menunjukkan efektivitasnya. Dalam formulasi gel, komponen gelling agent merupakan faktor kritis yang dapat mempengaruhi sifat fisika gel yang dihasilkan (Ansel, 2008).

Basis gel HPMC merupakan gelling agent yang sering digunakan dalam produksi kosmetik dan obat, karena dapat menghasilkan gel yang bening, mudah larut dalam air, dan mempunyai ketoksikan yang rendah (Setyaningrum, 2013). Selain itu HPMC (Hidroxy Propyl Methyl Cellulose) menghasilkan gel yang netral, jernih, tidak berwarna, stabil pada $\mathrm{pH}$ 3-11, mempunyai resistensi yang baik terhadap serangan mikroba, dan memberikan kekuatan film yang baik bila mengering pada kulit (Suardi, 2008).

Humektan merupakan suatu bahan yang dapat mempertahankan kelembaban sehingga kadar air dapat dipertahankan serta dapat menurunkan aktivitas air sehingga dapat melindungi produk dari pemanasan dan menjaga kesegaran produk (Soearti, 2016). Gliserin menyebabkan rasa berat dan tacky, sehingga untuk menutupi hal tersebut, penggunaan gliserin sebagai humektan perlu dikombinasi dengan humektan lain. Propilen glikol stabil digunakan dalam suatu sediaan bila dikombinasikan dengan gliserin (Zocchi, 2001).

\section{METODE PENELITIAN}

\section{Bahan}

Bahan yang digunakan dalam penelitian ini adalah, HPMC (Hidroxy Propyl Methyl Cellulose), propil paraben, propilen glikol, gliserin dan aquadest.

\section{Peralatan}


Peralatan yang digunakan dalam penelitian ini antara lain timbangan analitik (Precisa XB 220 A), Gelas kimia, magnetic stirrer, pH meter, Viskometer Rheosys, dan alat daya sebar.

\section{PROSEDUR PENELITIAN}

\section{Pembuatan Basis Gel}

Pembuatan basis gel dilakukan dengan cara, HPMC dengan variasi konsentrasi 3\%, 5\% dan 7\% dikembangkan dengan aquadest, kemudian didiamkan selama kurang lebih 24 jam, selanjutnya ditambahkan propil paraben sebagai pengawet yang telah dilarutkan dalam campuran gliserin dan propilen glikol sebagai humektan dan diaduk dengan bantuan stirrer dengan kecepatan 4-6 rpm hingga homogen. Selanjutnya dilakukan evaluasi karakteristik fisik basis gel selama 4 minggu, dimana dalam 1 minggu dilakukan 1 kali pengujian karakteristik fisik basis gel dan disimpan pada suhu ruang. Karakteristik fisik basis gel yang di uji yaitu pengukuran viskositas, $\mathrm{pH}$, daya sebar, organoleptis (bau, warna, dan konsistensi) dan homogenitas. Kemudian dipilih salah satu konsentrasi HPMC yang memiliki karakteristik fisik yang memenuhi persyaratan atau standar yang telah ditetapkan.

Tabel 1. Rancangan Formulasi Basis Gel HPMC

\begin{tabular}{lccc}
\hline \multirow{2}{*}{ Nama bahan } & \multicolumn{3}{c}{ Konsentrasi bahan dalam formulasi basis gel (\%) } \\
\cline { 2 - 4 } & $\mathbf{F}_{\mathbf{1}}(\boldsymbol{\%})$ & $\mathbf{F}_{\mathbf{2}}(\boldsymbol{\%})$ & $\mathbf{F}_{\mathbf{3}}(\boldsymbol{\%})$ \\
\hline HPMC & 3 & 5 & 7 \\
Propilen glikol & 15 & 15 & 15 \\
Propil paraben & 0,025 & 0,025 & 0,025 \\
Gliserin & 10 & 10 & 10 \\
Aquadest & $\operatorname{ad} 100$ & $\operatorname{ad~} 100$ & $\operatorname{ad} 100$ \\
\hline
\end{tabular}

\section{Evaluasi Karakteristik Basis Gel}

Pengukuran viskositas sediaan dilakukan dengan cara menggunakan viskometer Rheosys. Sebanyak 0,5 g basis gel diletakkan permukaan silinder, kemudian viskositasnya diukur dengan viskometer yang dilengkapi dengan spindel dengan kecepatan 12 rpm. 
Pengukuran $\mathrm{pH}$ sediaan dilakukan dengan cara menggunakan alat $\mathrm{pH}$ meter digital. Alat $\mathrm{pH}$ meter dicelupkan pada sediaan gel, setelah tercelup dengan sempurna, dinyalakan alat $\mathrm{pH}$ meter dan selanjutnya ditunggu hingga angka pada layar $\mathrm{pH}$ meter menunjukkan angka yang stabil, $\mathrm{pH}$ sediaan gel harus sesuai dengan pH kulit yaitu 4,5 - 6,5 (Tranggono, 2007).

Pengukuran daya sebar yaitu sebanyak 0,5 g sampel gel diletakan diatas kaca bulat berdiameter $15 \mathrm{~cm}$, kaca lainnya diletakan diatasnya dan dibiarkan selama 1 menit, diameter sebar gel diukur. Setelahnya, ditambahkan $150 \mathrm{~g}$ beban tambahan dan didiamkan selama 1 menit lalu diukur diameter yang konstan (Astuti, 2010). Daya sebar 5-7 cm menunjukkan konsistensi semisolid yang sangat nyaman dalam penggunaan (Garg, 2002).

Pengujian organoleptik dilakukan dengan cara pengamatan langsung bentuk warna, dan bau dari gel yang dibuat. Gel biasanya jernih dengan konsistensi setengah padat (Ansel, 2008).

Pengujian homogenitas dilakukan dengan cara mengoleskan sampel gel pada sekeping kaca atau bahan transparan lain yang cocok, sediaan harus menunjukkan susunan yang homogen dan tidak terlihat adanya butiran kasar.

\section{HASIL DAN PEMBAHASAN}

\section{Pembuatan Basis Gel}

Formula basis gel terdiri dari HPMC, propil paraben, propilen glikol, gliserin dan aquadest. Hidroksipropilmetilselulosa (HPMC) digunakan sebagai agen pembentuk gel selain itu pengemulsi, pensuspensi, pengental dan penstabil pada sediaan topikal HPMC adalah basis nonionik sehingga tidak akan membentuk kompleks dengan garam-garam logam atau ion-ion organik serta tidak akan menimbulkan endapan yang tidak larut. Selain itu, HPMC dapat mencegah terbentuknya sedimen. Dibandingkan dengan metilselulosa, HPMC memberikan warna yang lebih jernih pada sediaan. HPMC digunakan karena tidak toksik dan mengiritasi . Propil paraben digunakan sebagai pengawet. Pengawet diperlukan karena sediaan gel memiliki kandungan air yang tinggi sehingga menyebabkan mudah terkontaminasi mikroba. Propilen glikol digunakan sebagai humektan yang 
akan mempertahankan kandungan air dalam sediaan sehingga sifat fisik dan stabilitas sediaan selama penyimpanan dapat dipertahankan. Gliserin juga berfungsi sebagai humektan atau penahan lembab yang dapat meningkatkan daya sebar sediaan dan melindungi sediaan dari kemungkinan menjadi kering. Penggunaan kombinasi gliserin dan propilen glikol secara bersamaan didasarkan pada kenyataan bahwa gliserin mempunyai viskositas yang rendah namun gliserin memberi kelembutan sehingga nyaman digunakan, sedangkan propilen glikol memiliki viskositas yang lebih tinggi namun kurang nyaman dalam aplikasinya karena ada pengaruh rasa lengket saat digunakan. Humektan dengan viskositas rendah menyebabkan mudahnya tercampur dalam suatu sediaan, sedangkan humektan dengan viskositas yang tinggi dapat mencegah terjadinya pemisahan emulsi. Aquadest berfungsi sebagai pelarut dalam formulasi gel.

\section{Pengujian Viskositas}

Tabel 2. Hasil Pengukuran Viskositas

\begin{tabular}{cccc}
\hline \multirow{2}{*}{ Pengamatan } & \multicolumn{3}{c}{ Nilai Viskositas (pa.S) } \\
\cline { 2 - 4 } & HPMC 3\% & HPMC 5\% & HPMC 7\% \\
\hline M0 & 4,69 & 5,49 & 9,53 \\
M1 & 4,76 & 6,08 & 9,00 \\
M2 & 4,69 & 6,03 & 9,78 \\
M3 & 4,61 & 5,29 & 8,88 \\
M4 & 4,96 & 6,43 & 8,87 \\
Rata-Rata & 4,74 & 5,86 & 9,21 \\
Standar deviasi & 0,14 & 0,54 & 0,37 \\
\hline
\end{tabular}

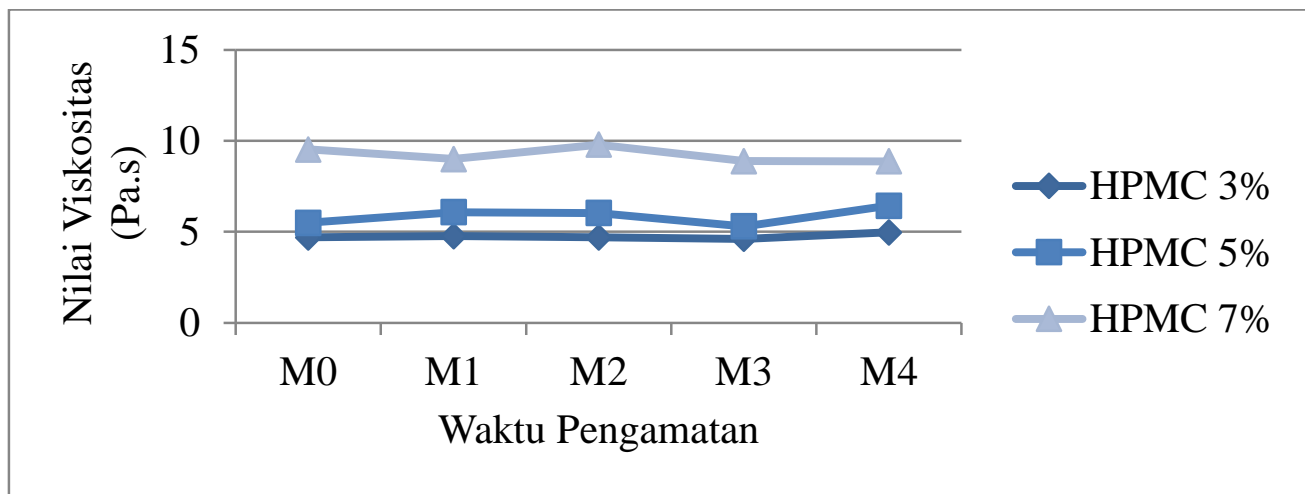

Gambar 1. Hasil Pengukuran Viskositas 
Pengujian viskositas bertujuan untuk menentukan nilai kekentalan suatu zat. Semakin tinggi nilai viskositasnya maka semakin tinggi tingkat kekentalan zat tersebut. Hasil yang diperoleh terjadi peningkatan viskositas pada masing masing formula seiring meningkatnya konsentrasi HPMC yang digunakan. Untuk konsentrasi HPMC 3\% memiliki viskositas yang stabil sedangkan HPMC 5\% dan $7 \%$ nilai viskositasnya mengalami naik turun selama 4 minggu penyimpanan. Nilai viskositas sediaan gel yang baik yaitu 2-50 Pa.S. Dari rata-rata viskositas dari HPMC 3\% yaitu 4,74 \pm 0,14 Pa.s, HPMC 5\% yaitu 5,86 $\pm 0,54$ Pa.s dan HPMC $7 \%$ yaitu dan 9,21 \pm 0,37 Pa.s. Sehingga yang memenuhi persyaratan viskositas yaitu HPMC 3\%, 5\%, dan $7 \%$.

\section{Pengujian pH}

Tabel 3. Hasil Pengukuran pH

\begin{tabular}{cccc}
\hline \multirow{2}{*}{ Pengamatan } & \multicolumn{3}{c}{ Nilai pH } \\
\cline { 2 - 4 } & HPMC 3\% & HPMC 5\% & HPMC 7\% \\
\hline P0 & 5,14 & 4,63 & 3,98 \\
P1 & 5,17 & 4,87 & 3,99 \\
P2 & 5,22 & 4,81 & 4,04 \\
P3 & 5,18 & 4,83 & 4,11 \\
P4 & 5,17 & 4,51 & 4,1 \\
Rata-Rata & 5,17 & 4,73 & 4,04 \\
Standar deviasi & 0,02 & 0,15 & 0,04 \\
\hline
\end{tabular}

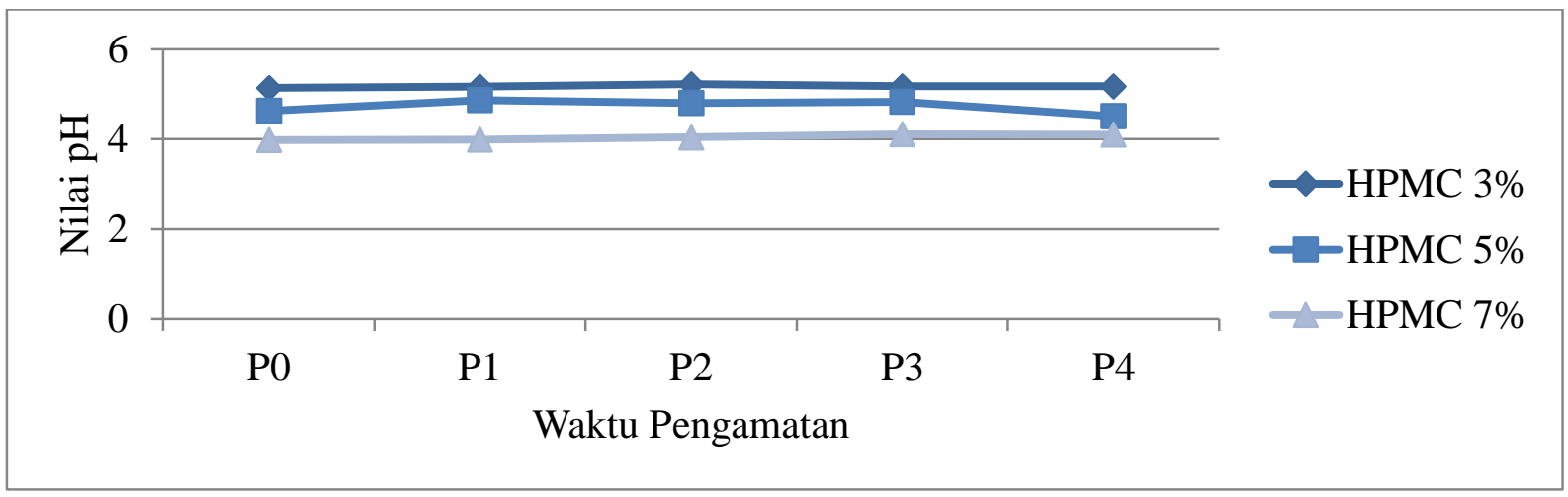

Gambar 2. Hasil Pengukuran $\mathrm{pH}$

Pengukuran $\mathrm{pH}$ bertujuan untuk mengetahui apakah sediaan yang dihasilkan dapat diterima $\mathrm{pH}$ kulit atau tidak, karena hal ini berkaitan dengan keamanan dan kenyamanan sediaan ketika digunakan. Apabila tidak sesuai dengan 
pH kulit maka sediaan dapat menyebabkan iritasi yang mengakibatkan ketidaknyamanan dalam penggunaan. Berdasarkan pada hasil pengamatan dari masing-masing sediaan gel selama penyimpanan 4 minggu pada suhu ruang, dapat dilihat terjadi naik turunnya nilai $\mathrm{pH}$ pada sediaan. Tetapi perubahan $\mathrm{pH}$ tidak terjadi secara signifikan sehingga masih berada dalam range $\mathrm{pH}$ normal kulit yaitu 5,0-6,8. Dari rata-rata nilai $\mathrm{pH}$ dari HPMC 3\% yaitu 5,17 $\pm 0,02$, HPMC 5\% yaitu 4,73 $\pm 0,15$ dan HPMC 7\% yaitu 4,04 $\pm 0,04$. Sehingga yang memenuhi persyaratan nilai pH yaitu HPMC $3 \%$.

\section{Pengujian Daya Sebar}

Tabel 4. Hasil Pengukuran Daya Sebar

\begin{tabular}{cccc}
\hline \multirow{2}{*}{ Pengamatan } & \multicolumn{3}{c}{ Daya sebar $(\mathrm{cm})$} \\
\cline { 2 - 4 } & HPMC3\% & HPMC 5\% & HPMC 7\% \\
\hline P0 & 5,53 & 4,06 & 3,46 \\
P1 & 5,53 & 3,95 & 3,21 \\
P2 & 5,50 & 3,71 & 2,85 \\
P3 & 5,33 & 3,72 & 3,01 \\
P4 & 4,86 & 3,93 & 2,87 \\
Rata-Rata & 5,37 & 3,87 & 3,08 \\
Standar deviasi & 0,20 & 0,09 & 0,13 \\
\hline
\end{tabular}

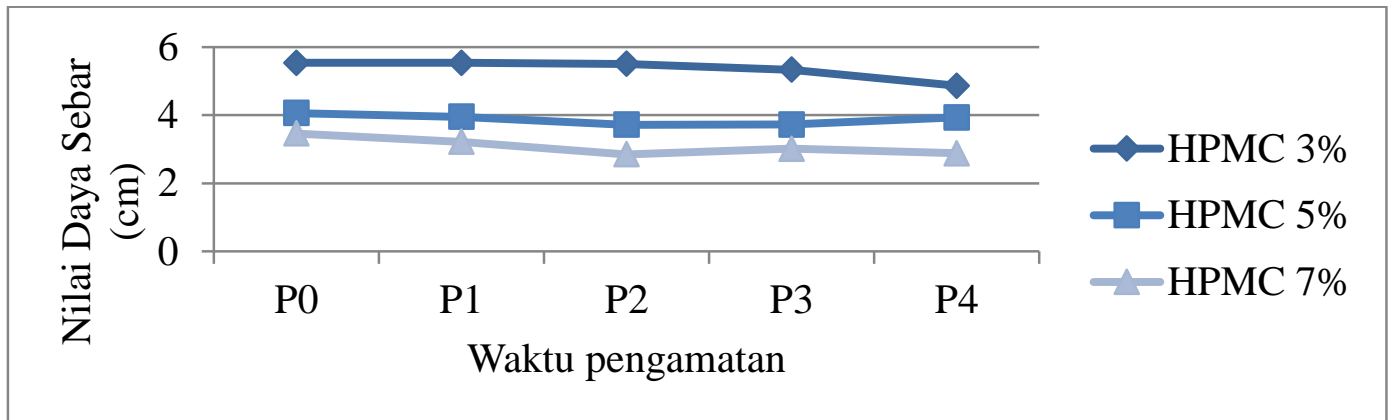

Gambar.3 Hasil Pengukuran Daya Sebar

Pengujian daya sebar bertujuan untuk mengetahui seberapa baik sediaan gel menyebar di permukaan kulit, karena dapat mempengaruhi absorbsi obat dan kecepatan pelepasan zat aktif di tempat pemakaiannya. Suatu sediaan yang baikdan lebih disukai bila dapat menyebar dengan mudah di kulit dan nyaman digunakan. Hasil rata-rata yang diperoleh untuk konsentrasi 3\%, 5\% dan 7\% berturut-turut 
adalah $5,37 \pm 0,20 \mathrm{~cm}, 3,87 \pm 0,09 \mathrm{~cm}$, dan 3,08 $\pm 0,13 \mathrm{~cm}$. Sehingga yang memenuhi persyaratan daya sebar yaitu HPMC $3 \%$.

\section{Pengujian Organoleptis}

Tabel 5. Hasil Pengujian Organoleptis

\begin{tabular}{cccc}
\hline \multirow{2}{*}{ Konsentrasi HPMC } & \multicolumn{3}{c}{ Organoleptis } \\
\cline { 2 - 4 } & Konsistensi & Warna & Bau \\
\hline $3 \%$ & Agak cair & Bening & Tidak berbau \\
$5 \%$ & Agak kental & Bening & Tidak berbau \\
$7 \%$ & Kental & Bening & Tidak berbau \\
\hline
\end{tabular}

Berdasarkan hasil pengamatan organoleptis yang dilakukan selama 4 minggu terhadap basis gel, diketahui bahwa basis gel dengan konsentrasi HPMC $3 \%, 5 \%$ dan $7 \%$ tidak mengalami perubahan, dimana warna yang dihasilkan bening, dan tidak berbau. Sedangkan konsistensi basis gel HPMC 3\% agak cair, 5\% agak kental dan 7\% kental Hal ini disebabkan karena semakin tinggi konsentrasi HPMC maka semakin kental basis gel yang diperoleh. Sehingga yang memenuhi persyaratan organoleptis yaitu HPMC 3\%,5\%, dan $7 \%$.

\section{Pengujian Homogenitas}

Tabel 6. Hasil Pengamatan Homogenitas

\begin{tabular}{cc}
\hline Konsentrasi HPMC & Homogenitas \\
\hline $3 \%$ & Homogen, tidak ada butiran kasar \\
$5 \%$ & Homogen, tidak ada butiran kasar \\
$7 \%$ & Homogen, tidak ada butiran kasar \\
\hline
\end{tabular}

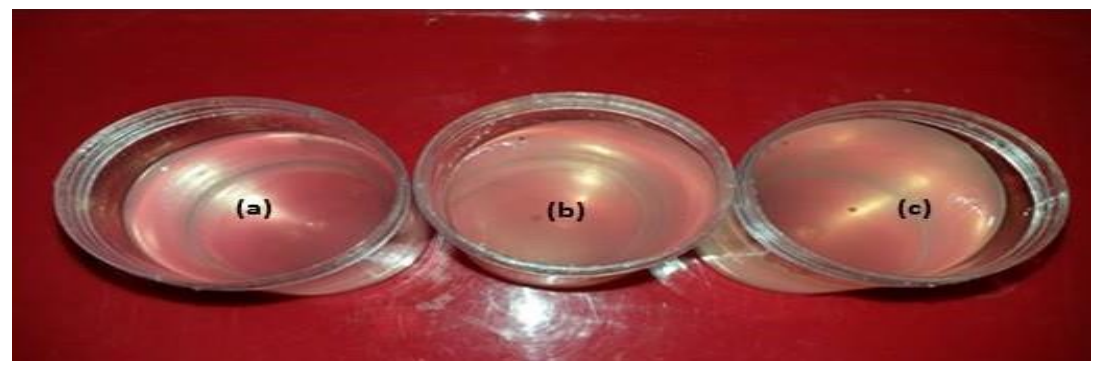

Gambar 4. Basis Gel Konsentrasi HPMC (a) 3\% ; (b) 5\% ; dan (c) 7\%. 
Pemeriksaan homogenitas terhadap sediaan basis gel menunjukan bahwa semua sediaan tidak memperlihatkan adanya butiran kasar pada saat dilihat secara visual. Hal ini menunjukkan bahwa sediaan yang dibuat mempunyai susunan yang homogen.

\section{KESIMPULAN}

Berdasarkan hasil penelitian yang telah dilakukan maka dapat disimpulkan bahwa basis gel dengan konsentrasi HPMC 3\% memenuhi persyaratan dengan nilai viskositas yaitu 4,74 $\pm 0,14 \mathrm{~Pa} . \mathrm{s}$, nilai $\mathrm{pH}$ yaitu 5,17 $\pm 0,02$, daya sebar yaitu 5,37 $\pm 0,20 \mathrm{~cm}$, organoleptis yaitu berbentuk agak cair, berwarna bening dan tidak berbau serta homogen.

\section{DAFTAR PUSTAKA}

Ansel, HC. 2008. Pengantar Bentuk Sediaan Farmasi. Ed. 4. UI Press. Jakarta.

Astuti I. Y., D. Hartanti, dan A. Aminiati. 2010. Peningkatan Aktivitas Antijamur Candida albicans Salep Minyak Atsiri Daun Sirih (Piper bettle L.) Melalui Pembentukan Kompleks Inklusi dengan $\beta$-siklodekstrin. Majalah Obat Tradisional 15

Garg, A., Aggarwal, D., Garg, S., dan Sigla, A.K. 2002. Spreading of Semisolid Formulation: An Update. Pharmaceutical Tecnology.

Setyaningrum, N.L. 2013. Pengaruh Variasi Kadar Basis HPMC dalam Sediaan Gel Ekstrak Etanolik Bunga Kembang Sepatu (Hibiscus rosa sinensis L.) Terhadap Sifat Fisika dan Daya Antibakteri pada Staphylococcus aureus. Naskah Publikasi. Fakutas Farmasi Universitas Muhammadiyah Surakarta. Suardi, M., Armenia dan Anita, M. 2008. Formulasi dan Uji Klinik Gel Antijerawat Benzoil Peroksida-HPMC. Skripsi. Fakultas Farmasi Universitas Udayana. Denpasar. Bali.

Soerarti, W., Rasita, N., dan Himawati, E. R. 2016. Pengaruh Jenis Humektan Terhadap Pelepasan Asam Sitrat Dari Basis Gel Secara In Vitro. J. Phar. 4 (2) 
Tranggono, Retno, I., Latifah, Fatmah. 2007. Buku Pegangan Ilmu Pengetahuan Kosmetik. PT. Gramedia Pustaka Utama. Jakarta.

Zocchi, 2001, Skin-feel Agents dalam Paye, M., Barel, A.O., Maibach, H.I., Handbook of Cosmetic Science and Technology. Marcel Dekker. Inc., New York. 